\title{
ИДЕИ ДИФФЕРЕНЦИАЦИИ ОБУЧЕНИЯ НА ЭТАПЕ «РАЗВИТОГО СОЦИАЛИЗМА» (1965-1985)
}

\author{
Кувшинова Галина Анатольевна \\ канд.пед.наук \\ АНО ВО «Национальный институт дизайна»
}

\begin{abstract}
Аннотация: В этот исторический период (1965-1985) следующие формы дифференциации были реализованы посредством факультативов, основанных на индивидуальных предпочтениях и наклонностях обучающихся как формы дифференцированного обучения, разрастания ряда спецшкол с углубленным изучением определенных предметов, курсов по выбору, ученических производственных бригад, учебно-производственных комбинатов с целью приучения обучающихся к производственному труду.

Ключевые слова: Десятилетний период обучения в школе, гуманизация учебного процесса, инновационные преподаватели, факультативные занятия, специальные школы, ученические производственные бригады, учебнопроизводственные комбинаты, дифференцированное обучение.
\end{abstract}

\section{THE IDEAS OF DIFFERENTIATION OF EDUCATION AT THE PERIOD OF «DEVELOPED SOCIALISM» (1965-1985)}

\section{Kuvshinova Galina Anatolevna Candidate of Pedagogical Sciences}

\begin{abstract}
In this historical period (1965-1985), the following forms of differentiation are distinguished into vocational training, depending on the individual needs and inclinations of students as one of the forms of differentiated training, special schools of a number of individual subjects, electives, training and production plants, student production teams in order to improve the system of labor training.

Key words: Ten-year period of study at school, humanization of the learning process, innovative teachers, elective classes, special schools, student production teams, training and production complexes, differentiated education.
\end{abstract}




\section{НАУКА, ОБЩЕСТВО, КУЛЬТУРА: ПРОБЛЕМЫ И ПЕРСПЕКТИВЫ ВЗАИМОДЕЙСТВИЯ В СОВРЕМЕННОМ МИРЕ}

Исторический период 1965-1985 гг. характеризовался провозглашением периода «развитого социализма», отсутствием гласности и критики, превращением коммунистической партии в административную систему, сохранением высокого научного потенциала, лидирующего положения в ряде наук, космической и лазерной технике и вместе с тем, огромной утечкой «мозгов» за границу [См.: 1, с. 125].

Значительным явлением в области общественно-педагогического движения следует считать деятельность В.А. Сухомлинского, создавшего в конце 50-х - начале 60-х гг. систему, нацеленную на индивидуализацию и гуманизацию процесса обучения. В Павлышской школе была задумана и реализована система стимулирования у детей школьного возраста радости познания, обеспечения такой организации учебного процесса, при которой бы школьники с увлечением, органически соединяли научные знания с физическим трудом, а труд интеллектуальный и производительный с процессом нравственного развития.

Массовое движение учителей, работавших в целях улучшения процесса образования, появилось в различных регионах страны: в Липецке, Волгограде, Ростове-на-Дону, в Новосибирской области, в Алтайском крае, в Татарской АССР. В каждом из регионов выделилось свое направление работы преодоление второгодничества на основе оптимизации учебно-воспитательного процесса в школах или повышение эффективности урока на основе активизации познавательной деятельности учащихся. Все эти виды поиска сводились к одному: преодолеть догматизм и шаблон в обучении и воспитании школьников, изгнать из стен школы формализм [2, с.233].

Необходимо обратить внимание еще на одно обстоятельство - учителя искали связь непосредственно между преподаванием и педагогической наукой. В работах педагогов и психологов были выяснены основные аспекты проблемы: психологическая структура познавательного интереса, значение и сущность интересов школьника, источники, определяющие их стойкость и глубину, возрастные особенности развития познавательных интересов, методы и приемы их формирования и др.

В 1964 г. происходили изменения в области образования. ЦК КПСС и Совет Министров СССР приняли постановление о сокращении срока обучения в средней общеобразовательной школе с одиннадцати до десяти лет. Изменения коснулись срока обучения и в средних общеобразовательных трудовых 


\section{НАУКА, ОБЩЕСТВО, КУЛЬТУРА: ПРОБЛЕМЫ И ПЕРСПЕКТИВЫ ВЗАИМОДЕЙСТВИЯ В СОВРЕМЕННОМ МИРЕ}

политехнических школах с производственным обучением. В августе 1964 г. ЦК КПСС и Совет Министров СССР постановили:

1. Установить в средних общеобразовательных трудовых политехнических школах с производственным обучением на базе восьмилетней школы вместо трехлетнего двухлетний срок обучения.

2. Перевод средних общеобразовательных трудовых политехнических школ с производственным обучением на новый срок обучения осуществить в течение двух лет, начиная с 1 сентября 1964 г. Обязать министерства просвещения и министерства народного образования союзных республик внести соответствующие изменения в учебные планы в программы общеобразовательных школ, обеспечить планомерный и организованный перевод средних школ на новый срок обучения» [3, с. 93].

ЦК КПСС и Советы Министров союзных республик обязали министерство просвещения принять меры к надлежащей постановке производственного обучения учащихся старших классов средних школ и обеспечить укрепление и дальнейшее развитие материальной базы для их производственной подготовки на предприятиях, в совхозах и колхозах.

Однако в 1966 г. в Закон о школе были внесены частичные изменения, в соответствии с которыми была отменена обязательная профессиональная подготовка в общеобразовательной школе. Это было связано с переводом средней общеобразовательной школы на десятилетний срок обучения и отсутствием во многих школах необходимых условий для осуществления обязательной профессиональной подготовки учащихся. Профессиональное обучение, в зависимости от индивидуальных потребностей и склонностей учащихся, как одна из форм дифференцированного обучения, в таких школах должна была проводиться за счет времени, выделяемого по учебному плану на трудовую подготовку учащихся, а также в порядке кружковой и факультативной форм работы [4, с.37].

Введение новых учебных программ в средней школе началось в 1966 г. и было завершено в основном в 1971-1972 гг. В соответствии с постановлением партии и правительства в школе повсеместно началось систематическое преподавание основ наук с четвертого года обучения. Кроме этого, было решено ввести с VII класса факультативные занятия по выбору школьников, что являлось одной из форм дифференциации обучения. 


\section{НАУКА, ОБЩЕСТВО, КУЛЬТУРА: ПРОБЛЕМЫ И ПЕРСПЕКТИВЫ ВЗАИМОДЕЙСТВИЯ В СОВРЕМЕННОМ МИРЕ}

Необходимость пересмотра учебного плана и программ средней школы была вызвана необходимостью привести содержание обучения в школе в соответствие с современным уровнем развития науки, техники и культуры, найти новое решение вопросов о формах и содержании подготовки учащихся к труду в связи с изменением сроков обучения в старших классах, нормализовать учебную нагрузку учащихся, устранить серьезные недостатки в качестве знаний учащихся. Одновременно требовалось по-новому определить содержание трудового и политехнического обучения в школе. Трудовое обучение в I-VIII классах, сложившееся к 1966 г., в основном себя оправдывало. Считалось, что его дальнейшее улучшение возможно путем усовершенствования его содержания, организации и методов обучения.

Подготовка к труду учащихся старших классов давала положительные результаты только в тех школах, в которых она строилась в соответствии с индивидуальными потребностями школьников, возрастающим уровнем развития науки и техники и на основе применения знаний основ наук. Так было в школах, осуществлявших трудовую подготовку учащихся с широкой постановкой опытнической работы в сельском хозяйстве, при специализации учащихся по прикладной математике, прикладной химии, электро- и радиотехнике и др.

Но в большинстве школ учащиеся готовились к труду по таким профессиям, для овладения которыми общее образование в объеме средней школы и длительный срок обучения не являлись необходимыми. Кроме того, выбор профессий, по которым готовились школьники, часто производился без учета потребностей общества, способностей и желаний учащихся. Уже это требовало серьезных изменений в системе подготовки учащихся средней школы к практической деятельности. Осознавалась перегрузка программ и учебников материалом для обязательного изучения, что порождало поверхностное изучение основ наук.

В 1967 г. был подготовлен и введен в действие учебный план начальных, восьмилетних и средних школ. Анализ плана показал, что значительно сократилось количество часов, отводимое на изучение биологии, физики, химии. Трудовое обучение интегрировалось в один учебный предмет, однако, производственная практика и факультативные занятия не были изъяты из учебного плана, и на них высвобождалось довольно много учебного времени, что положительно сказывалось на внедрении политехнического образования в 


\section{НАУКА, ОБЩЕСТВО, КУЛЬТУРА: ПРОБЛЕМЫ И ПЕРСПЕКТИВЫ ВЗАИМОДЕЙСТВИЯ В СОВРЕМЕННОМ МИРЕ}

школе с учетом склонностей и потребностей учащихся. Таким образом, осуществлялось дифференцированное обучение в области политехнического образования.

Сравнение учебных планов, действовавших до принятия Закона об образовании 1958 г., когда учащиеся испытывали значительную перегрузку при изучении обязательных дисциплин, и план, введенный в 1968 г. после пересмотра учебных программ и планов в 1966 г., приводит нас к заключению, что количество часов по обязательным дисциплинам значительно уменьшилось по сравнению с 1959 г., в том числе значительно уменьшилось и количество часов, отводимое на трудовое обучение. Это разгрузило программу обучения. Однако, факультативных занятий стало больше. Подобный учебный план, который был разработан в 1968 г., практически не меняясь, просуществовал до середины 70-х гг. прошлого века.

В 1977-1978 уч. г. общее количество часов с I по X класс, распределялось примерно одинаково между предметами гуманитарного и естественноматематического циклов (соответственно 44\% и 41\%). Однако внутри каждой параллели классов это соотношение могло меняться. В средних и старших классах, где, кроме русского языка, литературы, математики, биологии, географии, преподавались еще и физика, химия, астрономия, черчение, гуманитарный цикл сокращался до $30 \%$, а естественно-математический возрастал до $50 \%$ с лишним. Неизменным, по сравнению с учебным планом 1968 г., остался лимит учебного времени на занятия трудом и физической культурой - по 2 часа в неделю. 2-4 часа факультативных занятий в VII-X классах по выбору школьников отводилось на углубленное изучение основных курсов, т.е. здесь наблюдается сокращение учебного времени по сравнению с учебным планом 1968 г.

Наряду с типовым учебным планом для общеобразовательной школы имелись видоизмененные планы для специальных школ: школ с преподаванием ряда предметов на иностранном языке, с углубленным изучением математики, физики, химии, литературы, изобразительного искусства, санаторно-лесных школ, вечерних (сменных) школ работающей молодежи. Характерной чертой этих планов являлось то, что в них независимо от типа школ был предусмотрен необходимый объем общеобразовательной подготовки. Вместе с тем имелись существенные различия по сравнению с типовым учебным планом. 


\section{НАУКА, ОБЩЕСТВО, КУЛЬТУРА: ПРОБЛЕМЫ И ПЕРСПЕКТИВЫ ВЗАИМОДЕЙСТВИЯ В СОВРЕМЕННОМ МИРЕ}

В условиях завершения перехода ко всеобщему среднему образованию все большее место в общеобразовательной подготовке в конце 70-х гг. ХХ в. занимали средние профессионально-технические училища. Содержание обучения в них складывалось из профессионально-технического и общеобразовательного циклов, которые шли параллельно в течение трех лет. Профессионально-технический цикл включал производственное обучение, специальную технологию, материаловедение, техническое черчение, основы экономики труда и производства. В общеобразовательный цикл входили все предметы, которые преподавались в старших классах средней школы, но с некоторым сокращением их объема. Иностранный язык и эстетика изучались факультативно.

В 60-70-е гг. существовали различные формы дифференциации учебного процесса: факультативные занятия, спецклассы и спецшколы с углубленным изучением ряда предметов (математики и вычислительной техники, физики и агробиологии, гуманитарных предметов и др.).

Средняя общеобразовательная школа с углубленным теоретическим и практическим изучением отдельных учебных предметов (гуманитарного и естественно-математического профилей) обеспечивала оканчивающим еe углубленное овладение знаниями и навыками по избранным учебным дисциплинам, развивала способности в соответствии с интересами и наклонностями учеников, способствовала сознательному выбору профессии. Школа с углубленным изучением ряда отдельных предметов являлась основной формой дифференциации обучения в 70-80-х гг. ХХ в. Эти школы открывались в соответствии с постановлением ЦК КПСС и Совета Министров СССР от 10 ноября 1966 г. №874 «О мерах дальнейшего улучшения работы средней общеобразовательной школы», в котором говорилось о том, что школы с углубленным теоретическим и практическим изучением отдельных учебных предметов открываются в составе IX-X классов. Кроме этого, в нем говорилось, что в школе могут одновременно функционировать классы с углубленным изучением нескольких учебных предметов.

Число учащихся в этих классах не превышало 35 человек, практические занятия, предусмотренные учебным планом, проводились в двух подгруппах одного класса. Школы с углубленным теоретическим и практическим изучением отдельных предметов работали по учебным программам, утвержденным Министерством просвещения РСФСР в соответствии с типовым 


\section{НАУКА, ОБЩЕСТВО, КУЛЬТУРА: ПРОБЛЕМЫ И ПЕРСПЕКТИВЫ ВЗАИМОДЕЙСТВИЯ В СОВРЕМЕННОМ МИРЕ}

учебным планом для этих школ. Знания учащихся по всем предметам оценивались на общих основаниях.

В 60-х гг. были созданы физико-математические школы-интернаты при Новосибирском, Московском университетах. В их учебную программу включались разделы высшей математики, классическая математика дополнялась современной. Курс физики опирался на высшую математику, уровень изложения приближался к университетскому. В целом объем учебного материала включал не менее 50\% университетских курсов общей физики и математики.

Наиболее широко распространенной формой дифференциации в 60-е гг. явились факультативные занятия. Они были предназначены для развития творческих сил старшеклассников, стимулирования их самообразования. В учебном плане на факультативные занятия отводились специальные часы. Программы факультативов разрабатывались как учителями, так и специалистами по методике обучения, утверждались Министерством просвещения СССР. На практике учителя чаще всего выбирали факультативы, представлявшие собой дополнение или расширение основного курса. Но к середине 70-х гг. во многих школах факультативные занятия стали превращаться в дополнительные занятия по подготовке учащихся в вуз.

В 1975 г. министр просвещения А.И. Данилов утвердил положение о факультативных занятиях в общеобразовательных школах РСФСР. В нем говорилось о том, что факультативные занятия должны иметь целью углубление общеобразовательных дисциплин и трудовой политехнической подготовки, а также способствовать развитию разносторонних интересов и способностей учащихся VII-X классов. Программы и учебные пособия факультативных курсов утверждались Министерством просвещения РСФСР. Основным фактором зачисления учащихся в группы по изучению факультативных курсов являлся учет интересов школьников. При проведении факультативных занятий рекомендовалось использовать различные формы и методы работы с учащимися: лекции, семинары, практикумы, лабораторные занятия, экскурсии, рефераты, доклады. У изучивших факультативный курс в свидетельстве о восьмилетнем образовании, а также в аттестате о среднем образовании указывалось название изученного факультативного курса без выставления оценки. Факультативы вели учителя-предметники, а также преподаватели вузов, специалисты производства и сельского хозяйства, 


\section{НАУКА, ОБЩЕСТВО, КУЛЬТУРА: ПРОБЛЕМЫ И ПЕРСПЕКТИВЫ ВЗАИМОДЕЙСТВИЯ В СОВРЕМЕННОМ МИРЕ}

имеющие соответствующую подготовку. Каждый факультативный курс рассчитывался не менее чем на 35 часов в год [5, с.29-31].

Опыт ведения факультативных занятий показал, что в конце 70-х - в начале 80-х гг. факультативы превратились в курсы для ликвидации пробелов в знаниях учащихся, их также использовали для того, чтобы провести дополнительный урок, если учитель какой-либо материал не успел объяснить учащимся. Факультативные занятия стали обязательными в каждой школе в старших выпускных классах в середине 80-х гг. Их использовали для того, чтобы лучше подготовить учащихся к сдаче выпускного экзамена. Факультативы были вынуждены посещать практически целые выпускные классы.

Наибольшее распространение в рассматриваемый период получили школы с преподаванием ряда предметов на иностранном языке. В этих школах по сравнению с массовыми почти в три раза увеличивалось время, отводимое на изучение иностранного языка. В школах с преподаванием ряда предметов на иностранном языке недельная нагрузка учащихся VI-X классов составляла от 33 до 38 уроков. В V-VII классах учащиеся занимались иностранным языком ежедневно, а в VIII-X классах - четыре раза в неделю; факультативные занятия в этих школах не были предусмотрены.

В первые годы существования школ с преподаванием ряда предметов на иностранном языке были сделаны попытки вести на иностранном языке все предметы, затем только гуманитарные. Возникли сложности с программнометодическим обеспечением. Встал вопрос о создании специального курса страноведения с элементами истории, географии, культуры страны изучаемого языка, который преподавался бы на иностранном языке [6, с.78-86.].

Школы с преподаванием ряда предметов на иностранном языке создавались в крупных городах, обучаться в них считалось престижным, в основном в них обучались дети служащих, процент учеников из семей рабочих был незначителен. Возродилась дифференциация по социальному положению как одна из форм дифференциации. Эту форму дифференциации рассматривает И.М. Осмоловская [7, с.67]

В 70-х гг. ХХ в. начала совершенствоваться деятельность ученических производственных бригад в колхозах и совхозах. Ученические производственные бригады также относятся к одной из форм дифференциации обучения на основе профессионального ориентирования учащихся. В начале 


\section{НАУКА, ОБЩЕСТВО, КУЛЬТУРА: ПРОБЛЕМЫ И ПЕРСПЕКТИВЫ ВЗАИМОДЕЙСТВИЯ В СОВРЕМЕННОМ МИРЕ}

70-х гг. на Ставрополье произошел полный охват учащихся VII-X классов сельских школ этими бригадами. Новым в работе бригад явился высокий уровень их материально-технической оснащенности, круглогодичная производственная и учебно-воспитательная работа, рациональная организация труда, совместная целенаправленная деятельность колхозов (совхозов) и школ по формированию у учащейся молодежи черт и качеств тружеников сельскохозяйственного производства. Большинство ученических бригад в Ставропольском крае стало структурными подразделениями колхозов $[8$, с.5253]. Важным показателем эффективности работы, проводившейся в ученических бригадах, являлось то, что выпускники сельских школ, члены этих бригад в основном оставались работать в сельскохозяйственном производстве.

В середине 70-х гг. ХХ в. в стране получила распространение новая форма организационно-педагогического обеспечения трудового обучения и воспитания, профессиональной ориентации и профессионального отбора межшкольные учебно-производственные комбинаты (МУПК). МУПК являлись одной из форм дифференцированного обучения, их деятельность осуществлялась в соответствии с постановлением Совета Министров СССР от 23 августа 1974 г. [9]. Основными задачами МУПК являлись ознакомление учащихся с трудовыми процессами и содержанием труда рабочих на предприятиях; осуществление профессиональной ориентации учащихся с целью подготовки их к сознательному выбору профессии; обучение школьников первоначальным навыкам труда по избранной профессии.

В 1978-79 уч. г. в СССР было создано 414 МУПК, в которых обучалось свыше 500 тысяч учащихся старших классов городских школ (33\% от всего контингента учащихся старших классов городских школ) [10, с.6]. Комбинаты оснащались современным оборудованием. К обучению учащихся привлекались высококвалифицированные специалисты производства. Дифференциация обучения в МУПК была направлена на профессиональную подготовку учащихся в объеме средней школы. Профессиональная ориентация здесь давала возможность не только практически знакомиться с различными специальностями, но и овладевать ими. Подбор профессий и количество обучавшихся в МУПК находились в прямой зависимости от потребности в трудовых ресурсах предприятий и организаций, которые находились в городе.

Так, по данным крайоно, одним из лучших в Ставропольском крае являлся МУПК в г. Пятигорске. Комбинат готовил учащихся по 18 профессиям, 


\section{НАУКА, ОБЩЕСТВО, КУЛЬТУРА: ПРОБЛЕМЫ И ПЕРСПЕКТИВЫ ВЗАИМОДЕЙСТВИЯ В СОВРЕМЕННОМ МИРЕ}

в которых нуждались города-курорты КМВ. Среди самых востребованных профессий считались: секретарь-делопроизводитель, младшая медсестра, оператор ЭВМ, мастер по художественной росписи, водитель грузового транспорта, младший продавец, повар-кулинар и др. Летом старшеклассникиучащиеся МУПК проходили учебно-производственную практику на базовых предприятиях г. Пятигорска. Они выполняли ученические нормы выработки продукции, работая на промышленных предприятиях, стройках, в санаториях, столовых, магазинах, тем самым вносили посильный вклад в выполнение народно-хозяйственного плана. Все это приближало трудовую подготовку старшеклассников к современному производству, расширяло участие трудовых коллективов в воспитании юной смены. На комбинате во внеучебное время проводилась работа по техническому творчеству, учащиеся привлекались к рационализаторской и изобретательской деятельности [8, с.53-55]. МУПК посещали учащиеся IX-X классов один раз в неделю. Количество учебных часов, предназначенных для получения профессии, было значительно меньше, чем в ПТУ, но ежегодная производственная практика компенсировала недостаток учебных часов, так как практика длилась один месяц. По окончании МУПК выпускникам присваивалась квалификация и выдавалось свидетельство об окончании МУПК с оценками по изученным предметам.

Педагогическая общественность отмечала, что организация трудового обучения и воспитания в МУПК способствовала повышению уровня педагогического процесса в общеобразовательной школе, расширяла его научный и политехнический характер, профориентационную направленность. Более половины выпускников, получивших квалификационные разряды, так или иначе связывали свою деятельность с тем видом труда, который они начали осваивать в учебно-производственном комбинате [10, с.10-11].

В 1965-1985 гг. в период застоя тормозилась всякая яркая, подлинно творческая инициатива и вместе с тем расцветала «показуха». В эти годы выдвигались многочисленные «почины» и «инициативы». Примером такого рода «начинаний» могут быть названы попытки партийных органов Москвы и Московской области, а также работников системы народного образования организовать движения учителей под девизом «Каждому школьнику - глубокие и прочные знания», «От творческого учителя - к творческому коллективу», «Каждого школьника научить учиться, жить и работать по-коммунистически», «Образцовому коммунистическому городу - образцовые школы». Однако, 


\section{НАУКА, ОБЩЕСТВО, КУЛЬТУРА: ПРОБЛЕМЫ И ПЕРСПЕКТИВЫ ВЗАИМОДЕЙСТВИЯ В СОВРЕМЕННОМ МИРЕ}

несмотря на все старания, они быстро исчезали, соприкоснувшись с реальной жизнью и не оказав никакого реального влияния на школу.

Вместе с тем с большим трудом пробивал себе дорогу подлинно новаторский опыт, который воплощал в себе потребности школы своего времени и поэтому вызывал заинтересованный отклик учителей. Именно на этой основе и возникло общественно-педагогическое движение 80-х гг.

Новаторский поиск педагогов, заявивших о себе в конце 70-х - начале 80х гг., связан с именами ленинградских педагогов Т.И. Гончаровой и Е.Н. Ильина, московской учительницы С.Н. Лысенковой, донецкого педагога В.Ф. Шаталова, грузинского ученого-педагога Ш.А. Амонашвили и др. Анализ идей, наблюдений, непосредственной деятельности этих учителей, обобщивших результаты своей работы в написанных ими книгах, позволяет сделать вывод о том, что в своих поисках они воплотили глубокую заинтересованность передовых школьных педагогов в коренном усовершенствовании учебновоспитательного процесса и выходе из того тупика, в котором оказалась школа. Учителя-новаторы, как впоследствии их стали называть, стремились найти такие формы и методы организации учебного процесса, которые позволили бы увлечь ученика, вооружить его прочными знаниями, преодолеть формализм школьной жизни и главное - сделать обучение в школе подлинно воспитывающим, воздействующим не только на ум, но и на душу ученика. Пути к решению этих задач они видели в нравственной направленности обучения, в единстве интеллектуального и эмоционального факторов, в развитии активности и самостоятельности, выработке личного отношения ученика к знаниям, в воспитании интереса и стремления к познанию. Учителяноваторы стремились приобщить школьников к ежедневному напряженному умственному труду, вооружить их методическими приемам, позволявшими им «учиться победно» (В.Ф. Шаталов), постичь радость познания. Необходимым условием всей этой работы являлось сотрудничество, взаимопонимание учителей и учеников. Неслучайно содержание деятельности учителейноваторов получило название «педагогика сотрудничества» [7, с.34].

В целях совершенствования учебного процесса в 80-е гг. наметился ряд направлений исследований, которые возникли в связи с реализацией реформы школы: межпредметные связи как фактор формирования личности; совершенствование связей между обучением основам наук, трудовым 


\section{НАУКА, ОБЩЕСТВО, КУЛЬТУРА: ПРОБЛЕМЫ И ПЕРСПЕКТИВЫ ВЗАИМОДЕЙСТВИЯ В СОВРЕМЕННОМ МИРЕ}

обучением и профориентацией; всестороннее развитие личности учащихся с учетом взаимосвязи учебных предметов и внеклассной работы и др.

Таким образом, в рассматриваемый нами период происходили коренные изменения в области образования. Осуществлялся повсеместный переход средних общеобразовательных школ на десятилетний срок обучения. Переход ко всеобщему среднему образованию был связан с совершенствованием трудового обучения и воспитания, подготовкой к труду.

В этот исторический период выделяются следующие формы дифференциации: профессиональное обучение, в зависимости от индивидуальных потребностей и склонностей учащихся как одна из форм дифференцированного обучения, школы с углубленным изучением ряда отдельных предметов, факультативы, учебно-производственные комбинаты, ученические производственные бригады с целью совершенствования системы трудового обучения. Дифференциация содержания образования коснулась разработки и усовершенствования учебных программ в связи с переходом ко всеобщему обязательному среднему восьмилетнему образованию, устранением перегрузок школьных программ и совершенствованием трудового обучения, а также подготовкой подрастающего поколения к труду. С этой точки зрения дифференциация обучения носила в основном политехнический характер.

В рассматриваемый нами период усиление внимания к ученику, к его формирующейся личности определялось общей принципиальной линией на укрепление связи обучения с жизнью, трудом, личным опытом учащихся. Это в свою очередь требовало переосмысления принципа индивидуализации и дифференцированного подхода к обучению. Дифференциация обучения стала рассматриваться как одно из необходимых условий активизации познавательной и творческой самостоятельной деятельности учащихся в процессе обучения. Индивидуализация и дифференциация обучения, осушествлявшаяся в разнообразных формах, имели важное значение в решении такой острой проблемы, как преодоление второгодничества и предупреждение неуспеваемости учащихся. 


\section{Список литературы}

1. Макаев В.В. История педагогики и образования. Опорные конспекты, тезисы, схемы. Учебно-методическое пособие для студентов. Издание 3-е. Пятигорск: ПГЛУ, 2004.

2. Очерки истории школы и педагогической мысли народов СССР (19611986 гг.) / Под ред. Ф.Г. Паначина, М.Н. Колмаковой, 3.И. Равкина. - М.: Педагогика, 1987.

3. Собрание постановлений Правительства СССР, 1964, №14.

4. Собрание постановлений Правительства СССР, 1966, №4.

5. Положение о факультативных занятиях в общеобразовательных школах РСФСР // Сборник приказов и инструкций, 1975.

6. Вендровская Р.Б. Уроки дифференцированного обучения // Советская педагогика, 1990, №11.

7. Осмоловская И.М. Как организовать дифференцированное обучение. М.: Сентябрь, 2002.

8. Макаев В.В. Школа и педагогическая мысль на Ставрополье в послевоенные годы (1945-1991). Монография. - Пятигорск: ПГЛУ, 2000.

9. Собрание постановлений правительства СССР, 1974, №18.

10. Школа и учебно-производственный комбинат. Материалы Всероссийского совещания директоров городских МУПК 13-14 июня 1979 года. - М, 1980.

(ㄷ) Г.А. Кувшинова, 2021 